\title{
Evaluation of Jamaica's PATH Conditional Cash Transfer Programme
}

\section{Citation}

Levy, Dan, and Jim Ohls. "Evaluation of Jamaica's PATH Conditional Cash Transfer Programme." Journal of Development Effectiveness 2.4 (December 2010): 421-441.

\section{Published Version}

http://dx.doi.org/10.1080/19439342.2010.519783

\section{Permanent link}

http://nrs.harvard.edu/urn-3:HUL.InstRepos:4908084

\section{Terms of Use}

This article was downloaded from Harvard University's DASH repository, and is made available under the terms and conditions applicable to Other Posted Material, as set forth at http:// nrs.harvard.edu/urn-3:HUL.InstRepos:dash.current.terms-of-use\#LAA

\section{Share Your Story}

The Harvard community has made this article openly available.

Please share how this access benefits you. Submit a story.

Accessibility 


\title{
Evaluation of Jamaica's PATH Conditional Cash Transfer Programme
}

\author{
Dan Levy \\ Lecturer in Public Policy \\ Center for International Development \\ John F. Kennedy School of Government \\ Harvard University \\ 79 JFK Street \\ Cambridge, MA 02138 \\ Phone: (617) 496-4281 \\ Fax: (617) 496-5747 \\ Email: Dan_Levy@harvard.edu \\ Jim Ohls \\ Senior Fellow \\ Mathematica Policy Research, Inc. \\ 600 Maryland Ave., SW, Suite 550 \\ Washington, DC 20024-2512 \\ Phone: (609) 466-1066 \\ Fax: (609) 799-0005 \\ Email: JOhls@mathematica-mpr.com
}

\section{Acknowledgments}

We are grateful to several officials in the government of Jamaica, particularly to Colette RobertsRisden and Trevor Smith at the Ministry of Labour and Social Security, and Carol WatsonWilliams at the Planning Institute of Jamaica for all their input and help in conducting the evaluation. We are grateful to Cornelia Tesliuc, Andrea Vermehren, Gloria Rubio, and Laura Rawlings from the World Bank, for useful comments and advice at various points in the project. Maxine Wedderburn and Deborah Bourne were instrumental in conducting the qualitative assessments. Peter Schochet provided insightful comments at various points in the evaluation. We are also grateful to seminar participants at Harvard University, The World Bank, Mathematica Policy Research, and APPAM's Annual Conference, for their comments and questions. Alex Hall, Alex Kent, Miki Satake and Ama Takyi provided outstanding research assistance. 


\section{Evaluation of Jamaica's PATH conditional cash transfer programme}

This paper summarizes the findings of an evaluation of the Programme of Advancement through Health and Education (PATH), a conditional cash transfer programme implemented by the Government of Jamaica. We find that PATH was generally implemented as intended; exhibited better targeting to the poor than other similar social assistance programmes in Jamaica; and had positive and statistically significant impacts on school attendance and number of preventive health care visits for children. We find no evidence, however, that PATH was able to affect longer-term outcomes such as marks, grade progression, or health care status.

\section{Introduction}

Conditional cash transfer (CCT) programmes have received significant attention from academics and policy makers alike over the past decade. These programmes, which provide cash transfers to households if they meet certain conditions (typically sending children to school regularly and going to health centres for preventive care), have now been implemented in many countries around the world. Fiszbein and Schady (2009) describe the global expansion of CCTs - the 'CCT wave' - in their insightful and comprehensive World Bank book. As they note, the fact that rigorous evaluation has been an important part of the implementation of many CCTs has contributed to their sustainability and replication.

CCTs have been found to produce significant positive effects on the use of both education and health services in many countries; however their impact on final outcomes such as wages, test scores, and health status is less established. As Fiszbein and Schady explain, this could be due to several factors, including household-level constraints on final outcomes and the poor quality of services available to CCT participants. Gaarder, Glassman and Todd (2010) also conclude based on their review of CCT impacts on health that although CCT programs have increased utilization of health services, the effect on deeper outcomes is less clear. Simply put, if service quality is low, increased utilization may not improve outcomes. Moreover, they suggest 
that increased demand for health services as a result of CCT interventions could lead to reduced service quality or crowding-out of other (non-beneficiary) households, thus dampening or negating the benefits of the program.

CCTs are not implemented in the same way everywhere. For example, the amount of the cash transfer and how this amount was derived varies across programs. The types of benefits received also vary across programs. In some countries the programs only offer cash, whereas in other countries the programs offer cash plus other benefits or services such as food items, nutrition-related talks, and so forth. CCTs also vary in the extent to which conditioning requirements are monitored and enforced, the quality of education and health services in the country, and the barriers to utilization of health and education services. The fact that CCTs can differ significantly in their structure and in the conditions facing policymakers and program administrators suggests that rigorous evaluation of CCTs as they are implemented remains very important.

This paper summarizes the findings of our evaluation of a CCT programme in Jamaica called PATH (Programme of Advancement through Health and Education). PATH was the cornerstone of the social safety net reform recently implemented in Jamaica and represents one of the largest social programmes in the country (Ayala, 2006). In assessing this programme, we aim to contribute to the growing collection of CCT evaluations and provide useful information regarding the specific case of Jamaica. At the same time, we hope to highlight some of the benefits of a 'mixed method' evaluation approach that combines standard quantitative methods with qualitative information to produce analysis that we believe is both more rigorous and more informative than that which could be attained through the use of either approach on its own. 
Our evaluation is structured around a quasi-experimental regression discontinuity design and draws on both quantitative and qualitative data to determine whether PATH is reaching its intended population and increasing the human capital of poor households, as measured by school attendance and health care usage. The quantitative analysis uses detailed household survey data collected at two stages (baseline and follow-up) for two samples of households (participant and comparison groups). Our qualitative analysis is based on focus groups and interviews. This type of information allowed us to assess how the programme was implemented, identify specific strengths and weaknesses of PATH's approach, and present a more detailed picture of PATH's impact on poor households than is possible with quantitative evidence alone.

This paper is organized as follows: Section two describes PATH’s context, goals, and structure in greater detail, and briefly summarizes our analysis of PATH's implementation and targeting. Section three presents our survey data. Section four describes our empirical strategy and offers discussion of relevant methodological issues. Section five presents the results of our impact analysis and robustness tests. Finally, section six offers a summary and conclusions.

\section{Background: context, implementation, and targeting.}

Poverty in Jamaica is concentrated among the young and the elderly, in rural areas, among female-headed households, and among large families. Although poor children are typically enrolled in school, their attendance can be erratic, a fact that families tend to attribute to 'money problems.' Indeed, the World Bank found that parents reported lack of money prevented them from sending their children to school and providing them with food, clothing, and shelter (The World Bank 2001b). The poor in Jamaica also suffer from lower quality and accessibility of 
health care services than the non-poor. Moreover, immunization rates for infants up to 11 months of age fell from 93 per cent in 1993 to 85 per cent in 1999 (The World Bank 2001c).

Before the development of PATH, the Government of Jamaica financed 54 safety net programmes through 12 ministries. This was generally perceived to be an ineffective way of delivering social assistance (The World Bank 2001c). Some of these programmes aimed to target the poor but failed to reach a significant share of the target population, and others were not designed to target the poor at all. A high proportion of the poor was apparently unaware of available benefits, and even if they were aware, the high cost of attaining a relatively low level of benefits likely deterred many eligible beneficiaries from applying. The Government of Jamaica developed PATH as the centrepiece of a wholesale reform of these programs, with the goal of knitting the safety net into a fiscally sound and more efficient system of social assistance for the poor and vulnerable with a particular focus on the extremely poor. The PATH programme replaced three major income support programs—-the Food Stamps Programme, the Poor Relief Programme, and the Public Assistance Programme—and its design reflects four major goals: (1) development of a universal targeting system based on a proxy means test to increase transparency, reduce administrative costs, and improve targeting; (2) consolidation of the existing cash and in-kind transfer programs to ensure a meaningful level of benefits and an efficient delivery system, link benefits to desirable behaviour changes that promote human capital investment, and target social assistance to groups with especially high needs; (3) improvements in targeting, efficiency, and impact of various school-based programmes; and (4) development of systems to monitor and evaluate programmes by building on existing instruments such as the annual Jamaica Survey of Living Conditions. 
The remainder of this section is divided into three parts. First we describe the formal structure of the PATH programme and how it was designed to work. Second, we offer additional insight into its operations based on two qualitative assessments consisting of site visits, interviews, and focus groups. Third, we draw on household data to compare how well PATH targets the poor in comparison to other Jamaican programs.

\section{PATH Overview}

PATH is organized around two components: (1) child assistance grants, which provide health and education grants for eligible poor children through age 17, conditional on children through age six visiting a health clinic every two months during the first year and twice per year thereafter, and children ages six to 17 attending at least 85 per cent of school days; and (2) social assistance grants, which provide grants to poor pregnant or lactating mothers, elderly poor (over age 65), and poor, disabled, and destitute adults under age 65. While social assistance grants were initially conditional on regular health clinic visits, this conditionality was discontinued shortly after the programme was launched. The average monthly benefit per individual receiving a grant at the time of data collection was about US\$6.50. ${ }^{1}$ Figure one provides a simple logic model that helps conceptualize what the programme aimed to accomplish. The distinction between short- and long-term outcomes is worth highlighting briefly at this stage: The programme benefits are conditioned on short-term outcomes, namely increased attendance at school and health centres for children, so we would expect that the programme's effects on these outcomes, if they exist, would be evident immediately after a beneficiary enrols. Long-term outcomes (depicted as dotted lines in the diagram) may take more time to affect and are more closely related to the ultimate goal of increasing human capital among the poor. 


\section{[Figure 1 about here]}

To participate in the programme, a household must apply to its Ministry of Labour and Social Security (MLSS) parish office and provide detailed demographic and socio-economic information that allows MLSS to calculate a household score used to determine programme eligibility. At the time of the evaluation, about 245,000 individuals had signed up for PATH, of which about 180,000 received benefits in a typical month. ${ }^{2}$ MLSS staff are responsible for assessing compliance with the education and health conditioning requirements, and payments are distributed through local post offices.

\section{Implementation Analysis}

Our implementation analysis is based on site visits conducted in two rounds during the evaluation (Wedderburn, Hamilton and Bourne, 2004; Wedderburn, Morris and Hamilton, 2005). In each round, visits were made to five randomly chosen parishes throughout Jamaica, and at each site focus groups were conducted with randomly selected groups of beneficiaries as well as one-on-one interviews with representatives from MLSS parish offices, schools, health care centres, and post offices. Focus group participants and interviewees provided detailed information about the eligibility determination process, education and health requirement enforcement mechanisms, benefit adequacy, and the process of benefit disbursement. Our analysis is summarized briefly here and is referenced when we present the programme impact findings in section five.

It is clear that MLSS was generally successful in setting up operations that implemented the PATH concept, and the programme was widely viewed by stakeholders as having 
accomplished its basic mission successfully. Survey results also indicate that most PATH participants had satisfactory transactions with the programme.

Still, there are a number of areas where improvements are possible, of which three warrant specific mention. First, there were often delays in making PATH payments available to beneficiaries, leading to uncertainty about timing that imposes substantial costs and sometimes hardships on beneficiaries. Focus group participants indicated delays of up to one week past the announced date when their checks were to be available. This can cause significant problems for beneficiaries since many PATH households have no spare resources and therefore experience difficulty managing their finances while waiting for delayed payments. For instance, a late check can mean lunch money is not available for school-aged children. In addition, beneficiaries often have to make numerous trips to the post office to obtain their check, a process that can be expensive in terms of time and, in some instances, bus fare or other travel expenses. Post office staff echoed beneficiary concerns about the late arrival of checks and also expressed concern about other issues including duplicate checks, incorrect names, erroneous suspensions, and delays in removing deceased beneficiaries from PATH lists.

Second, many stakeholders believed there were problems in the accuracy of the information used for enforcing school and health care participation conditions. Beneficiaries noted a tendency for MLSS to suspend their PATH benefits in response to incorrect compliance information. Approximately 10 per cent of the children in focus group households had been suspended for various reasons, most often nonattendance at school, and in the majority of cases the parent disputed the reason. Generally, the error was thought by the parents to lie with the PATH office rather than with the school records. 
Parents also stressed the fact that MLSS does not make retroactive payments in the case of an error, and that satisfying requirements can be burdensome, particularly the obligation to provide a doctor's certificate whenever a child is absent for health reasons. To them, the PATH documentation requirements meant an unnecessary expense that was often beyond the means of the household. They felt that a letter from a parent to the school should suffice to explain a child's illness-related absence. Teachers echoed some of these concerns but also noted that parents do not always cooperate and are usually late in providing information with respect to an illness resulting in a child's absence. In addition, teachers commented that MLSS staff take a long time to correct errors, meaning reinstatement can be a lengthy process.

Third, beneficiaries reported difficulties and delays in the eligibility determination process and when obtaining information from MLSS representatives about their cases. Beneficiaries felt that the information used to determine selection was inadequate, and that the length of time required for approval and the gap between approval and disbursement of benefits were onerous. In all the focus groups, beneficiaries spoke of knowing individuals who are in need but whose applications were rejected. They also indicated that some beneficiaries' economic status should have prevented acceptance into the programme. Respondents clearly felt that the assessment of applicants requires an in-depth investigation. Specifically, they argued that PATH staff should make routine field visits to evaluate application information and ensure that those most in need receive benefits. School staff echoed concerns about the accuracy of eligibility determination and felt that school guidance counsellors are ideally placed to coordinate and contribute to eligibility recommendations. ${ }^{3}$

\section{Targeting Analysis}


An important reason for creating PATH was to increase the ability of Jamaica's social safety net system to channel assistance to households and individuals most in need of financial help. Our analysis of a detailed survey of the consumption levels and circumstances of a random sample of PATH participants indicates that the programme has been fairly successful in this respect. In particular, 58 per cent of benefits went to the poorest quintile of the population (figure two). This compares favourably with results attained by other social programmes; the corresponding figure for Food Stamps, one of the main programmes PATH was meant to replace, is just 36 per cent. About four of every five PATH beneficiaries fall into the bottom two quintiles of the consumption distribution as compared with only about three in five Food Stamp participants.

\section{[Figure 2 about here]}

Another possible way to assess how effective PATH was at targeting the poor is to compare PATH with other CCTs in terms of the percent of program beneficiaries under the poverty line, which is available for several evaluations. These comparisons are challenging for various methodological reasons. A key reason is that countries have different definitions of poverty, and countries with high poverty rates will likely fare better using this indicator of targeting than some other indicators that are less commonly reported (such as the coverage rate, described below). Nevertheless, we did make some comparisons between PATH and PROGRESA (now Oportunidades) in terms of targeting effectiveness. Using each country's definition of poverty, PROGRESA fares better than PATH in that 74 per cent of PROGRESA's beneficiaries are poor (Skoufias, Davis, and Behrman, 1999), whereas only 58 per cent of PATH’s beneficiaries are poor. But Mexico’s poverty rate at the time was 52 per cent whereas Jamaica’s was only 20 per cent, so this finding is perhaps not so surprising. If we were to use a 
common poverty definition for the two countries, then PATH tends to look better than PROGRESA. For example, if we consider poor any household that falls below the $25^{\text {th }}$ percentile of consumption in their own country, 63 per cent of PATH beneficiaries are poor, whereas 39 per cent of PREGRESA beneficiaries are poor. Similarly, if we consider poor any household that falls below the $52^{\text {nd }}$ percentile of consumption in their own country (which corresponds to Mexico’s official poverty line), 89 per cent of PATH beneficiaries are poor, whereas 74 per cent of PROGRESA beneficiaries are poor.

Despite the fact that PATH's targeting effectiveness is better than that of other social programmes, our qualitative work revealed that stakeholders still see room for improvement. As noted above, focus group participants noted inequities in eligibility determination and suggested that greater in-person monitoring by MLSS staff_-including more visits to beneficiaries’ homes to verify information the households provided — could be useful in improving the targeting.

It is also useful to assess the extent to which PATH was able to reach the poor in Jamaica. We estimate PATH's coverage rate of the poor as follows: Around the time data collection began, the overall estimated poverty rate in Jamaica was about 20 per cent. With Jamaica’s population at approximately 2.6 million, the total number of Jamaicans living in poverty was 520,000. As noted above, the number of individuals receiving PATH benefits in a typical period during the evaluation was approximately 180,000 and, based on the data in figure two, 59 per cent of these enrolees were poor. Thus, PATH was reaching approximately 106,000 poor beneficiaries. Overall, therefore, the programme’s coverage rate was about 20 per cent. In assessing this estimate we should note that PATH was never funded at a participation level that would allow full coverage. The target number of beneficiaries in PATH was about 236,000, so 
even with 'perfect' targeting, the programme would have reached only about 45 per cent of the poor.

\section{Data}

Our impact evaluation is based primarily on survey data collected by the Statistical Institute of Jamaica (STATIN). Baseline and follow-up data were collected over two threemonth periods, ${ }^{4}$ roughly 18 months apart. STATIN was careful to interview participant and comparison groups at approximately the same rates over time to avoid any timing biases that could have occurred had one group been interviewed before the other. Response rates were similar for the two groups at approximately 91 per cent for the baseline survey and 82 per cent for the follow-up. A non-response analysis, available upon request, suggests that both groups of respondents are fairly representative of their respective survey samples.

These survey data were combined with administrative data on PATH applicants extracted from the Management Information System (MIS), which contains detailed information on the household characteristics of PATH participants obtained from the application form, as well as records of compliance with conditioning criteria (education attendance and health clinic usage). We extracted the relevant variables from MIS and applied consistency checks to the data.

Together, the data include a range of demographic, socioeconomic, and related information including health and education outcome variables. In our results (section five) we focus on three key outcome questions, two concerning school attendance and one concerning preventive health visits. On attendance, respondents were asked how many days children attend school in a typical four-week period, as well as in a specific reference period. The key question 
related to health was whether or not an individual had visited a health clinic for preventive care in the preceding 12 months.

\section{Empirical strategy}

Our empirical strategy exploits the fact that applicants were selected into the programme based exclusively on whether their eligibility score, computed by MLSS based on information provided during the application process, was lower than the cutoff value. We do this using a regression discontinuity design that compares applicants just below the threshold ('barely eligibles') with applicants just above it ('near eligibles'). We estimate several regressions in which the dependent variable is the outcome of interest (school attendance or health visits), the key explanatory variable is an indicator of whether an individual is a member of the participant group of barely eligibles, and a key control variable is the household eligibility score. The participant and comparison samples each consist of roughly 2,500 households that applied for PATH and had children; they differ, naturally, in that participant households scored at or below the cutoff value, whereas comparison households scored above this threshold.

The full regression discontinuity model used in our analysis is specified as follows, where $P A R T_{j}$ is the participant group indicator for household $j, f\left(\right.$ Score $\left._{j}\right)$ is some function of the household eligibility score, $X_{i j}$ is a vector of characteristics of individual $i$ in household $j$ including demographics, housing characteristics, and asset ownership, and $A P P D A T E_{j}$ is a set of binary indicators referring to the date on which household $j$ applied to PATH: ${ }^{5}$

$$
\text { Outcome }_{i j}=\beta_{0}+\beta_{1} \text { PART }_{j}+\beta_{2} f\left(\text { Score }_{j}\right)+\beta_{3} X_{i j}+\beta_{4} \text { APPDATE }_{j}+u_{i j}
$$


All regressions are run at the individual level, and Huber-White standard errors are used to account for within-family correlations. Moreover, since there is a binary indicator for each application date, all regressions are fixed-effects at the application date level.

Two key issues are (1) determining what functional form to use in entering the score into the estimation equation; and (2) assessing the extent to which the score really statistically accounts for differences between the participant and comparison groups. To address these issues, we ran 'placebo regressions' using data from the baseline survey. The idea is to estimate regressions similar to the one specified above, but using outcome data from the baseline survey (figure three). We conducted placebo tests using four different specifications for each of the four outcomes (a total of sixteen regressions). The specifications we estimated are (1) score enters linearly without household vector $X_{i j}$; (2) score enters in quadratic form without $X_{i j}$; (3) score enters in cubic form without $X_{i j}$; and (4) score enters linearly and the vector $X_{i j}$ of household characteristics is included. Given that the programme could not have affected the outcomes at baseline, we should expect the coefficient on the participation dummy to be insignificant if the regression discontinuity design is appropriate in this context.

The results from the placebo tests lend support to using a regression discontinuity design for estimating PATH's impacts. Figure three presents the results for each of the four outcome variables using placebo test specification four, in which score enters linearly and the vector of household characteristics $X_{i j}$ is included as a control. ${ }^{6}$ In general, the coefficient on the participant group indicator is not statistically significant: It is not significant for any of the regression specifications involving school attendance (in the reference period or in the typical period) or for health visits for the elderly. The participant indicator enters significantly at the 10 per cent level in just two of the sixteen placebo regressions, in both of which the dependent 
variable is health visits for children zero to six years old (specifications two and three, without household controls and with score included in quadratic and cubic form, respectively). Furthermore, the coefficients on score squared and score cubed are statistically insignificant in all specifications, which suggests that a linear specification of the score in the impact estimation regressions is a reasonable way to proceed. While we present findings based on this specification, the results are robust to other formulations.

\section{[Figure 3 about here]}

The regression discontinuity approach does not require the participant and comparison groups to be statistically similar since the scoring formula was the exclusive determinant of programme eligibility and should thus account for any differences between the two groups. Nevertheless, it is encouraging to note that the participant and comparison groups are fairly similar to each other key baseline characteristics related to education and health.

As shown in figure four, the two groups are generally comparable in terms of school enrolment, school attendance, and frequency of visits to health centres. Enrolment rates are very high (around 96\%) and respondents in both groups reported that enrolled children attended an average of 18 days per 20-day period. About three in four children attended school for 17 to 20 days, which would meet PATH's attendance requirement of 85 per cent of school days. Moreover, respondents from both groups tended to give similar reasons for not sending their children to school, and to have similar patterns regarding which health centres they visited.

\section{[Figure 4 about here]}

The participant group does, as expected, appear somewhat more disadvantaged than the comparison group in terms of socioeconomic characteristics, and the differences are larger in terms of characteristics related to PATH. As specified in the design, the scores on the PATH 
eligibility indicator are lower among participants. However, the average distance to the threshold is larger for the participant group than for the comparison group: All comparison group scores are clustered within 2 points of the cutoff level, but the distribution of participants ranged from just below the threshold to about 18 points below, with a median between five and 15 points below the cutoff level. ${ }^{7}$

\section{Impact analysis}

\subsection{Education-related outcomes}

Figure five presents results from regressions estimating the impact of PATH on school attendance using various specifications. In the first panel, the dependent variable is the number of days a child attended school in the specific 20-day reference period. In the simplest specification (specification one), which includes only the participant indicator, we find that

average reported school attendance in the reference period was a statistically significant 0.48 days higher among participants than among the comparison group. The estimated impact decreases slightly when we include the household eligibility score (specification two) but remains statistically significant. The estimated coefficient on the eligibility score is not statistically significant. Specifications three and four introduce the baseline attendance variable and the vector of household characteristics, respectively. Neither of these additions alters the statistical significance or basic magnitude of the impact estimate. As might be expected, the estimated coefficient on the baseline indicator is statistically significant.

The second panel of figure five presents similar data from the regressions run using reported attendance in a typical 20-day period as the dependent variable. These results are very similar to those discussed above. The estimated coefficient on the participant group variable is 
slightly higher, but the overall patterns of coefficients and significance levels are very similar. Taking the two panels together, we estimate the impact of PATH on school attendance to be between 0.50 and 0.55 additional days in a 20-day period. To put the magnitude of these impacts in perspective we attribute to PATH an increase in reported attendance from 16.60 days to 17.11 days (3\%) in the 20-day reference period, and an increase in reported attendance from 17.48 days to 18.03 days (3\%) in a typical 20-day period. At first glance, these changes may seem quite modest. But it is important to note that school attendance among the comparison group is quite high, with the average child attending about 17 days out of a 20-day school period (85\%). Given that there are days when children are sick or have other legitimate reasons not to be in school, it appears that there was little room for change in this measure.

\section{[Figure 5 about here]}

Another way to think about the magnitude of the effects is to examine the findings in relation to findings from evaluations of similar programmes in other countries. Such comparisons are complicated by the fact that most other conditional cash transfer (CCT) programmes have tended to focus on increasing enrolment rather than attendance, which is the focus of PATH. Still, in general, countries with baseline conditions similar to those in Jamaica have experienced education-related effects similar to those found with PATH.

Relevant information is available on eleven programmes in all—PATH and ten other programmes conducted in various countries. For the ten others, the outcome variable is the percentage of children enrolled in schools. Of all eleven, there were two programmes with baseline outcome values below 50 per cent, both of which produced estimated outcome improvement in excess of 10 per cent. There were five programmes with baseline outcome values between 50 and 80 per cent, of which two achieved improvements above 10 per cent and 
three achieved improvements of between 5 and 10 per cent. Finally, four programmes including PATH had baseline outcomes above 80 per cent and all four achieved improvements between 0 and 5 per cent (Fiszbein and Schady, 2009). The main implication for our current discussion is that if the outcome variable in percentage terms is already quite high, then the achievable change appears to be quite limited. Specifically, these findings suggest that the relatively small size of the PATH effect (in percentage terms) is not surprising, given that the starting attendance rate was quite high.

In interpreting the estimated effects on attendance, it is also important to note that, given our design, these estimates should be viewed as reflecting the impacts of PATH for the marginal PATH participants, that is, households near the eligibility cutoff for the programme. Essentially, the estimates reflect the expected rise in school attendance from enrolling in PATH for a household whose eligibility score was approximately at the cutoff level. This interpretation reflects the fact that, by virtue of the regression discontinuity evaluation design, our basic analytical comparisons are between households just below the cutoff (the participant group) and those just above (the comparison group). These impact estimates are therefore helpful in assessing the likely consequences of expanding or cutting PATH at the margin (that is, by changing the eligibility cutoff score). In particular, the estimates are of interest to policymakers who may be considering whether or not to expand PATH.

It is difficult at a formal level to generalize these findings to households whose eligibility scores were considerably below the cutoff; the extent to which the estimated impacts can be generalized depends on our assumptions about where the programme is most likely to have a larger impact. On the one hand, it is at least arguable that low-scoring households would, if anything, exhibit larger effects, since they had relatively more to gain from the assistance 
provided by PATH. To the extent that lower-income households can be expected to respond more strongly than other households to the PATH incentives, our estimates are conservative. On the other hand, poorer households could have been less likely to respond to PATH's incentives because they did not have the resources to do so or because they face more significant barriers to sending their children to school. In this latter case, our estimates would likely be larger in magnitude than PATH's impact for the average participant.

\section{Subgroup estimates}

Figure six provides evidence on whether various subgroups of the population are affected in different ways by PATH. Entries in the table are the estimated impacts of PATH expressed in days of attendance using regression specification four, which includes the eligibility score, baseline outcome and household characteristics. As shown in figure six, estimated impacts are very similar for boys and girls, and for different age groups, although the impacts tend to be somewhat smaller in the 10 to 12 age group. ${ }^{8}$ However, these differences are not statistically significant. The only substantial and statistically significant difference in impacts relates to the geographical area of residence. The residents of Kingston are estimated to have experienced noticeably larger effects than either residents of other cities or residents of rural areas.

\section{[Figure 6 about here]}

Some policymakers have speculated that the programme may have a larger effect on older children, given that they tend to have lower enrolment and attendance rates. Figure six does not provide strong evidence in support of this assertion: The magnitude of the impact estimates for children aged 13 to 17 tend to be higher than the corresponding magnitudes for other age groups, but these differences are not statistically significant. Moreover, we find no evidence 
within the 13 to 17 age group that the impact of PATH on school attendance was larger for older children. It is important to keep in mind, however, that this analysis involves fairly low sample sizes and hence low statistical power.

We also find no evidence that the impact of PATH was higher for children with low levels of attendance at baseline than for children with high levels of attendance. Children who were attending school fewer than 12 days in the 20-day reference period (which corresponds to the 10th percentile) and those who were attending fewer than 16 days (which corresponds to the 25th percentile) exhibited PATH impacts that were statistically indistinguishable from children who were attending more than 16 days in the 20-day reference period. Similar findings arise from the analogous analysis for school attendance in the 20-day typical period.

\section{Further analysis}

Participants' responses about their interactions with both PATH and the schools are a potential source of insight into what underlies the observed effects of PATH as reported above. For example, it is likely that the incentive effects of PATH depend in part on how often sanctions were exercised in cases of noncompliance with PATH requirements.

Approximately 26 per cent of the participant household children aged seven to 17 in the sample had their benefits reduced at some point while they were participating in PATH. According to the survey, the most common rationale for sanctions in the form of reduced benefits was failure to meet school attendance requirements. However, a significant number of respondents said they did not know why their benefits were reduced. This could reflect confusion on the part of respondents, but it could also reflect administrative errors. The latter would be consistent with findings from the qualitative assessments that some participants believed such 
errors occurred. Overall, the findings on sanctions suggest that PATH participants probably viewed them as a credible threat.

When asked in the follow-up survey to give the reason their children were absent from school during the reference period (if their child had been absent), the responses were similar by and large across the participant and comparison groups. However, the participants were much less likely than the comparison group to cite 'money problems' as a reason for absence (12\% versus $22 \%$ ) and were slightly more likely to cite illness. In contrast, in the baseline survey the percentage of participant group respondents who connected absences with 'money problems' was very similar to that of the comparison group. This suggests that one of the ways in which PATH encouraged attendance was providing the resources (such as transportation and lunch money) families needed in order to send their children to school.

While PATH had a positive effect on school attendance, it did not seem to have an effect on school achievement outcomes such as marks and advancement to next grade. Respondents were asked whether their child had graduated to the next highest education level at the end of the previous year and how their child's recent grades related to grades received in the previous year. Children in the participant group were slightly more likely than children in the comparison group to advance to the next grade (by about two percentage points), but this difference is small and not statistically significant. On the other hand, the participant group children were slightly more likely to report 'much worse' marks, but again this difference is small and far from statistically significant. We also assessed PATH's impacts on school advancement and marks using linear probability models specified analogously to the regressions described above. ${ }^{9}$ The results show no statistically significant differences between the participant and comparison groups. 
The statistical insignificance of PATH's estimated impacts on school achievement could reflect the fact that PATH has no effect on achievement, which would be consistent with the findings of other evaluations of CCT programs. But it is important to note that school achievement was not one of the major focal outcome variables specified when the analysis was planned. As a result, and given constraints on evaluation resources, the resources devoted to obtaining data on these outcomes were quite limited. It is therefore possible that a relatively lower level of statistical power in the analysis in this area is responsible for the apparent absence of an effect on these variables. It could also be that impacts on academic performance may take more time to emerge.

Another potential benefit of PATH is the possibility that by encouraging school attendance, the programme could reduce child labour. However, at least as reported by the children's parents, rates of child labour are extremely low in the sample (less than 2\%) and there are no significant differences between the participant and the comparison group.

In sum, there is no significant evidence that other outcomes such as advancement to next grade, marks earned, or child employment were affected by PATH. This implies that while the programme achieved its main education-related objective of increasing the frequency of school attendance, this increase may not have translated into improvements in deeper outcomes.

\subsection{Health-related outcomes}

To estimate the impact of PATH on health outcomes we used regression specifications analogous to those presented in the preceding section. Two age groups (children and the elderly) are included in our analysis of health care utilization, but since both the PATH requirements and the underlying determinants of health care utilization are different for these two groups, we 
conducted our impact estimation separately on the two samples. The first panel of figure seven, below, displays the results for children age zero to six, while the second panel presents our results from the four regression specifications run on elderly individuals (age 60 or older). The dependent variable for the analysis is the number of visits to a health practitioner in the last six months for preventive reasons.

\section{[Figure 7 about here]}

For children aged zero to six, the impact of PATH on usage of health care under specification four is estimated to be 0.28 visits per six-month period, an increase of approximately 38 per cent of the baseline value. The results using the other specifications are broadly consistent both in terms of magnitude and statistical significance, though the magnitude of impact is somewhat lower under specification one. Moreover, this result is broadly consistent with the corresponding finding on school attendance. In particular, in each of the regression specifications the coefficient on the participant group indicator is positive and statistically significant. Similarly, the coefficient on baseline version of the outcome is highly significant. In contrast to our impact estimates for school attendance, however, the eligibility score also enters significantly. In short, we find that PATH had a positive and statistically significant impact on preventive care health clinic visits by children in the programme.

Among the elderly, however, we find no statistically significant impact of PATH. The estimated coefficients on the participant group indicator are small and are not consistent in sign across the different specifications. The eligibility score variable is statistically insignificant in each specification where it is included, but the baseline number of preventive care visits remains highly significant. Overall, then, our findings are very different for the two sets of PATH participants: While children's use of preventive health care appears to have increased as a result 
of PATH, there is no evidence that the programme increased health care utilization among the elderly.

As with the education outcomes, our evaluation results in the area of preventive care utilization appear to be broadly consistent with findings from other countries, at least for children. Fiszbein and Schady (2009) indicate that in Colombia a CCT had an estimated effect on 'growth monitoring' of 23-33 percentage points, while the comparable figure in Honduras was an effect of approximately 20 percentage points. The increase for Jamaica in the average number of preventive care visits is consistent with these findings. The PATH results do differ from those of other countries in preventive care for adults. The review of other countries' experiences (Fiszbein and Schady, 2009) notes that for PROGRESA preventive visits went up for adults age 50 and over, in clear contrast with our finding for Jamaica of essentially no effects on health care utilization by the elderly. One possible explanation is that, as indicated earlier, PATH did not enforce sanctions for elderly who did not comply with the health requirement.

\section{Subgroup estimates}

Figure eight provides evidence on whether health utilization among various subgroups of the population was affected in different ways by PATH. The estimates are very similar for boys and girls and for different age groups, although the age zero to one group exhibits somewhat larger effects. However, because of the smaller sample sizes available for subgroup estimation, neither this difference nor the other cross-group differences in the table are statistically significant.

\section{[Figure 8 about here]}




\section{Further analysis}

As with the analysis of education outcomes, it is important to assess whether or not households had reason to view sanctions for not meeting the health care requirement as a credible threat. While the single largest reason for sanctions among families who had children seven to 17 years old was failure to meet school attendance requirements (true for $38 \%$ of households with a payment reduction), a substantial number of respondents (23\% of households with a payment reduction) reported having their payments reduced for failure to meet the health visit requirement. Furthermore, fewer households were at risk of the health sanction than were at risk of the education sanction, since among children the health visit requirement applies only to ages zero to six, while the school attendance requirement extends to the much larger six to 17 age group. When the analysis is restricted to families with children zero to six years old, 36 per cent of households report sanctions as a result of failure to meet school attendance requirements and 28 per cent report that failure to meet health attendance requirements led to sanctions. Finally, while the programme's initial design involved sanctions for elderly who did not meet the health requirement, this feature of the design was soon eliminated. Together, these observations suggest that sanctioning because of failure to meet the health visit requirement was quite common among children, and we conclude that the threat of being sanctioned was credible and may have had considerable incentive effects.

Respondents were also asked about their perception of the frequency of health visits, whether and why they had made a visit in the last six months, what services they received, which immunizations children had received, and how their health status compared to the previous year. The participant group is slightly more likely to report an increase in health visits over the preceding year than the comparison group, but the difference is quite small (8\% versus $5 \%$ ). 
Analysis using linear probability models (specified as above) also finds no statistically significant differences in perceptions between the participant and comparison groups. Given the earlier regression-based finding that PATH had a positive impact on the number of preventive visits by children, it is not clear why this does not reveal itself more clearly in reported perceptions.

PATH intended to increase use of preventive health services, and the surveys suggest that the participant group did indeed receive services that are generally regarded as constituting preventive care. Sixty per cent reported receiving immunizations, while 49 per cent received health-related advice. Eighteen per cent reported height measurement, and 31 per cent weight measurement. Only about 2 per cent received blood or urine tests, which are more likely to be diagnostic than preventive. In general these patterns are roughly similar for the comparison group, however the percentage reporting that they got health-related advice is slightly lower among the comparison group, and the percentage getting immunizations was somewhat higher.

When respondents had not made preventive care visits in the past six months, the most common reasons given were that the household did not think the visit was needed (51\% of the participant group), or they didn’t have the required money (33\%), meaning either money for the visit itself or for associated costs like transportation. In general, the response pattern is very similar for the comparison group, although parents of children in the participant group are slightly less likely than their counterparts in the comparison group to report that they failed to make preventive visits because they do not consider them necessary. Of participants who said that their children's usage of health care had gone up, 46 per cent indicated that the increase was due to the PATH requirement. Most of the rest indicated a change in health circumstances as the reason. 
Similar to our findings for education outcomes, there is no significant evidence that PATH has affected deeper health outcomes. There is no evidence that PATH was associated with higher immunization rates, though they were high to begin with, and the data provide no evidence that PATH led to increases in actual health status of children zero to six years old relative to previous years. The differences between the participant and comparison groups in how health status had changed over the evaluation period were all about one percentage point and not statistically significant. We explore this issue further by applying our four regression specifications and find no evidence that PATH affected health status, despite that it seems to have achieved its main health-related objective of increasing the frequency of preventive health visits for children zero to six years old. Two important caveats to keep in mind are that influencing these variables may take longer than the amount of time that the participant group was exposed to the programme, and that our measure of health status was a very crude one (since this was not one of the main outcomes to be studied in the evaluation).

\subsection{Robustness Analysis}

In this subsection we examine the extent to which our results are robust to different specifications of the regression equations and other features of our research design. In general, we find that the impact estimates presented above are robust.

First, as described above, the eligibility score spans a much wider range for the participant group $(1,017$ to 1,035$)$ than for the comparison group $(1,035$ to 1,037$)$. One important test, then, is whether the impact estimates are robust to restricting eligibility scores to those above a certain threshold $\left(1,025\right.$ and 1,030). ${ }^{10}$ The impact estimates continue to be positive and statistically significant for school attendance and for preventive health visits for children, and 
statistically insignificant for the elderly (figure nine, panels one and two). The magnitudes of the impact estimates on school attendance and children's health visits are as large as or larger than those in the unrestricted regressions. Thus restricting the participant group to households with high eligibility scores supports the main impact estimates presented above.

\section{[Figure 9 about here]}

Second, since the participant group tended to have applied later to the programme than the comparison group, we report impact estimates restricting the sample to include only households with application dates earlier than January 1, 2003 so that participant and comparison group members have similar application dates (figure nine, panel three). The impact estimates continue to be consistent with our main findings, presented above.

Third, some of the regression specifications used to estimate the impact estimates presented above include the baseline version of the outcome as the explanatory variable. To perform these regressions, we had to match (merge) observations in the follow-up data set with observations in the baseline data set. While it was relatively easy to match household-level information because of the presence of a consistent household ID variable in both data sources, matching at the level of the individual proved much more challenging. We used an algorithm to match at the individual level, and about 80 per cent of the matches were deemed to be 'high quality,' which means that we were reasonably sure that the person in the follow-up survey was the same as the person being matched to in the baseline survey. It is possible that our estimates are sensitive to different ways of dealing with the matches that resulted from the algorithm, so we explored several scenarios: in the first scenario we restricted our sample to high-quality matches; in the second scenario we used all matches but added binary explanatory variables indicating the quality of match to our regressions; in the third scenario we used a household 
average baseline measure instead of an individual one. The estimates are again consistent with our main results.

Another methodological concern is that households from the participant group may believe that they have an incentive to over-report attendance to school and health centres because of a perceived threat that STATIN could report back to the MLSS and generate sanctions for noncompliance with PATH. While this over-reporting concern is an issue in many similar studies, including the PROGRESA evaluation and many other evaluations of CCT programmes, we attempt to assess the likelihood and severity of this issue.

If participant group households are indeed over-reporting their outcomes, and if they are doing so to a greater extent than the comparison group, this would lead us to overstate the effects of PATH on these outcomes. While we cannot fully rule out that this may have happened to some extent, we present several arguments that lead us to believe that this concern is unlikely to explain our results. First, STATIN made it very explicit to households that their role was to collect data, and that they were not representing the government or administrators of any programme. Second, the questionnaire was designed in a way that the questions related to the key outcomes (school attendance and health centre visits) were asked before any questions about PATH. Third, other parts of the evaluation are generally supportive of the main impact findings. For example, the qualitative analysis suggests that parents were not only aware of the requirements of the programme but also reported sending their children to school and health centres more often.

Finally, because this concern cannot be fully discarded, we made conservative decisions in research choices in other parts of the analysis to try to compensate for the possible existence of some degree of over-reporting. For instance we do not adjust for take-up rates (76\% of 
participants actually enrol in the programme, a typical rate of take-up for evaluations of this kind) or for cross over (10\% of the comparison group had enrolled in PATH by the time of the follow-up).

\section{Conclusions}

PATH was effective at accomplishing its objective of encouraging households to send their children to school with greater regularity. Our results suggest that PATH has increased school attendance by approximately 0.5 days per month. The estimated increase is about 3 per cent over the baseline level, and it is statistically significant.

The size of this estimated effect should be viewed in the context of the fact that school attendance was already quite high in Jamaica. Specifically, the starting attendance rates were on the order of 85 per cent. Also, as in other countries, illnesses and other legitimate reasons for missing school are not uncommon. Together, these factors have constrained the possible size of the estimated effect of attendance-there was only limited room for improvement. Moreover, this effect is in line with estimates from other countries with similar baseline characteristics.

The results of discussions with parents and with school staff add depth to our understanding of the programme’s impact, and are consistent with the statistical findings. Parents had a reasonably clear understanding of the programme and the conditionality of the benefits. School staff indicated that in their experience, the parents were highly aware of the requirements of the PATH programme and were making good faith efforts to increase their children's attendance. In response to survey questions about the reasons their children might be absent from school, parents indicated that PATH had relieved some of the financial pressures associated with attendance, such as providing lunch money and payments for transportation. 
PATH was successful in meeting its objective of increasing the use of preventive health care for children in PATH households. Our analysis suggests that health care visits for children zero to six years old increased by approximately 38 per cent as a result of the programme. As with educational outcomes, the magnitude of this effect appears to be broadly consistent with the corresponding effects in other countries that have implemented CCTs. Our analysis of the impact of PATH on health care visits by the elderly, however, showed no evidence of effects on this group. One potential explanation is that early in the programme a decision was made not to enforce the conditionality requirements for this group of recipients.

While PATH was successful at increasing school attendance and preventive health visits, there is no evidence that it was able to affect longer-term outcomes such as marks in school, advancement to next grade, or health care status. There are at least two broad sets of explanations for this finding. The first set is methodological. It is possible that not enough time has elapsed to be able to observe the long-term effects of the programme. On average, the participant group had only received PATH benefits for about a year, and this simply may not be enough time for longterm effects to emerge. It is also possible that our research design lacks sufficient statistical power to detect these long-term effects, since these effects are probably small (especially given that they may only exist for the subset of children who actually increased their attendance as a result of the programme) and the variables used to measure long-term outcomes were likely to be susceptible to measurement error.

Another potential explanation behind the finding is that increasing attendance to school and health centres is simply not enough by itself to substantially improve longer-term outcomes. It is possible, as suggested by Fiszbein and Schady (2009), that improvements in the infrastructure of schools and health centres or in the quality of services provided in education 
and health are needed for increased attendance to translate into improved long-term outcomes. Assessing which of these two explanations is more prevalent in this context is necessarily speculative. But if the latter explanation is accurate, it suggests that to improve the human capital of poor households through PATH, policymakers may want to pay particular attention to the interaction between PATH and factors related to the delivery of education and health services. 


\section{Notes}

1. As a reference, the minimum wage in Jamaica for general workers at the time was about US\$160 per month (Planning Institute of Jamaica, 2005). A household receives a monthly grant amount based on the number of eligible members. Hence, a household with two children eligible for the health grant, two children eligible for the education grant, and one eligible adult would receive US\$32.50 (5 x US\$6.50) per month in the first year.

2. Although about 245,000 individuals had signed up for PATH, only about 180,000 received benefits in a given time period due to the fact that, for any given period, some beneficiaries did not comply with the PATH requirements.

3. Although focus group participants did not report corruption as a major issue, PATH's design does seem to allow for petty corruption among those responsible for verifying compliance with conditioning requirements. Such corruption has been documented in other CCT programs, such as in Bangladesh, and could be consistent with reports of bad information leading to discontinuation of benefits.

4. Interviews for the last 2 per cent of respondents were delayed by as much as two months.

5. Since the participant group was necessarily selected from the pool of applicants who had not enrolled in PATH at the time of baseline data collection, participants tend to have later application dates than members of the comparison group. We include the APPDATE $E_{j}$ indicators to control for this potential source of bias. However, it turned out that estimates of programme impacts were not affected much by this inclusion.

6. This placebo specification corresponds to the main specification used in our impact estimation regressions (presented in section 5).

7. This difference in the length of the score range between the participant and comparison households was produced by the decision to limit the sample to participants who had not yet received PATH Benefits. For more details, see Levy and Ohls (2003). In section 5.3 of this paper, we do sensitivity analysis and find that the impact estimates are robust to changes in the range of scores for the participant group.

8. Given the policy concern with the relatively low rate of school attendance by teenage boys, we also explored whether boys aged 13 to 17 years old were more likely to be affected by PATH than girls 13 to 17 years old. While the sample sizes are fairly small to draw very definitive conclusions, we found no evidence that this was the case.

9. We used a binary variable to indicate whether a household had reported better or much better marks relative to the previous year and then used a linear probability model (LPM) in which the dependent variable is the recoded binary variable, and the explanatory variables are the same as those used to estimate impacts on school attendance and preventive health visits. While models such as the ordered multinomial probit or logit are better suited for examining regressions using the kind of outcomes examined here, the LPM provides a reasonable approximation.

10. It is important to note that by imposing this restriction, we potentially gain comparability between the two groups (since they will be closer to each other in terms of the eligibility scores) but at the same time the statistical power of the design diminishes (since the sample size used in each estimation decreases). 


\section{References}

Ayala, F., (2006) Policy Brief 4: Programme of Advancement through Health and Education (PATH), Jamaica. (London: Overseas Development Institute Secretariat of the Inter-Regional Inequality Facility).

Fiszbein, A. and Schady, N. (2009) Conditional Cash Transfers: Reducing Present and Future Poverty (Washington: The World Bank).

Gaarder, M., Glassman, A., Todd, J. (2010) Conditional cash transfers and health: unpacking the causal chain. Journal of Development Effectiveness, 2(1), pp. 6-50.

Levy, D. and Ohls, J. (2003) Evaluation of Jamaica’s PATH Programme: Methodology Report (Washington: Mathematica Policy Research).

Levy, D. and Ohls, J. (2004) Evaluation of Jamaica’s PATH Programme: Targeting Assessment (Princeton: Mathematica Policy Research).

Levy, D. and Ohls, J. (2007) Evaluation of Jamaica’s PATH Programme: Final Report (Washington: Mathematica Policy Research).

Planning Institute of Jamaica. (2005) Economic and Social Survey of Jamaica.

Skoufias, E., Davis B., and Behrman J. (1999) "An Evaluation of the Selection of Beneficiary Households in the Education, Health, and Nutrition Program (PROGRESA) of Mexico," (Washington: International Food Policy Institute).

Wedderburn, M., Hamilton, P. and Bourne, D. (2004) First Qualitative Assessment on Jamaica's PATH Programme (Kingston, Jamaica: Hope Enterprises).

Wedderburn, M., Morris, T. and Hamilton, P. (2005) Second Qualitative Assessment on Jamaica’s PATH Programme (Kingston, Jamaica: Hope Enterprises).

The World Bank. (2001a) Jamaica Survey of Living Conditions (JSLC) 1988-98. (Washington: The World Bank).

The World Bank. (2001b) World Development Report 2000/01: Consultations with the Poor: Country Report, Jamaica. (Washington: The World Bank).

The World Bank. (2001c) Project Appraisal on a Proposed Loan in the Amount of US\$40 Million to Jamaica for a Social Safety Net Project. Report No. 22359-JM, The World Bank Sector Management Unit for Human Development, Caribbean Country Management Unit. 


\section{Figures}

Figure 1. PATH's logic model.

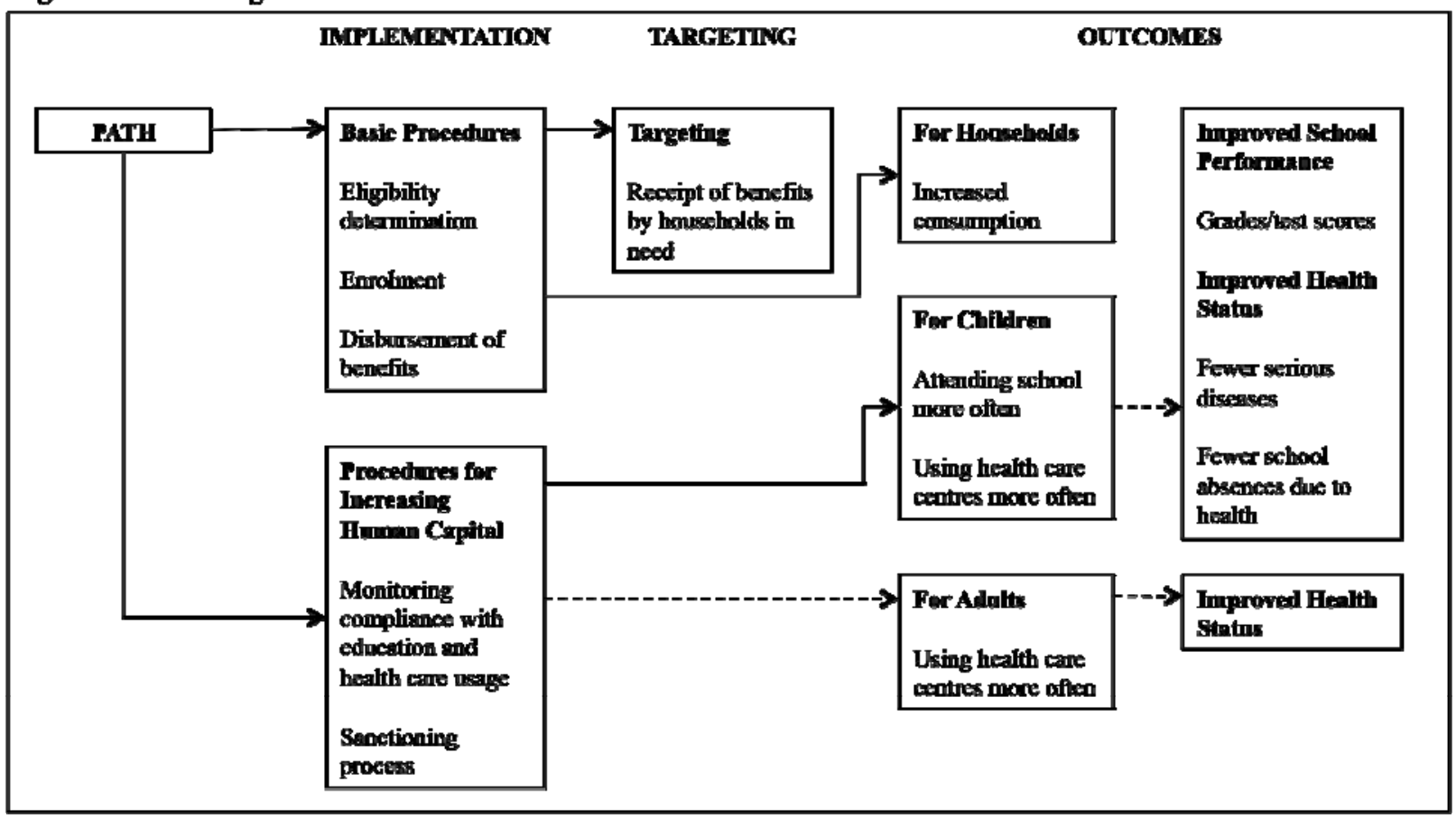

Figure 2. Overall assessment of PATH's targeting performance.

\begin{tabular}{lc}
\hline Income Quintile & Percent \\
\hline I & 58 \\
II & 21 \\
III & 14 \\
IV & 5 \\
V & 1 \\
\hline Poor & 59 \\
Extremely Poor & 27 \\
\hline
\end{tabular}

Figure 3. Placebo tests.

\begin{tabular}{lccccc}
\hline & \multicolumn{2}{c}{ School attendance } & & \multicolumn{2}{c}{ Attendance at health centres } \\
\cline { 2 - 3 } \cline { 5 - 6 } & Reference period & Typical Period & & Children 0-6 years & Elderly \\
\hline \multirow{2}{*}{ Participant group } & -0.171 & 0.128 & -0.035 & 0.018 \\
& $(0.21)$ & $(0.22)$ & $(0.09)$ & $(0.15)$ \\
Eligibility score & -0.015 & 0.03 & 0 & -0.002 \\
Household controls & $(0.02)$ & $(0.02)$ & & $(0.01)$ & $(0.01)$ \\
$N$ & 7,112 & Yes & 7,091 & Yes & Yes \\
\hline
\end{tabular}

Standard errors in parenthesis.

Regressions were run at the individual level. Huber-White standard errors were used to account for within-family correlations.

$* / * * / * * *$ Coefficient statistically significant at the $10 \% / 5 \% / 1 \%$ significance level. 
Figure 4. Baseline outcomes for particpant and comparison groups (percents, unless otherwise noted).

\begin{tabular}{|c|c|c|}
\hline Characteristics & $\begin{array}{l}\text { Participant } \\
\text { Group }\end{array}$ & $\begin{array}{l}\text { Comparison } \\
\text { Group }\end{array}$ \\
\hline \multicolumn{3}{|l|}{ Education: $:^{\mathrm{a}}$} \\
\hline Enrolled in school & 97 & 96 \\
\hline \multicolumn{3}{|l|}{$\begin{array}{l}\text { In a typical } 4 \text {-week period, how many days was child sent to } \\
\text { school? }\end{array}$} \\
\hline Mean (days) & 18 & 18 \\
\hline Median (days) & 20 & 20 \\
\hline Attending $0-14$ days & 10 & 10 \\
\hline Attending $15-16$ days & 16 & 16 \\
\hline Attending $17-20$ days & 73 & 74 \\
\hline \multicolumn{3}{|l|}{$\begin{array}{l}\text { During the reference period, how many days was child sent to } \\
\text { school? }\end{array}$} \\
\hline Mean (days) & 18 & 18 \\
\hline Median (days) & 20 & 20 \\
\hline Attending $0-14$ days & 7 & 7 \\
\hline Attending $15-16$ days & 16 & 16 \\
\hline Attending 17-20 days & 77 & 77 \\
\hline \multicolumn{3}{|l|}{ Health: } \\
\hline \multicolumn{3}{|l|}{ Visited health practitioner last 12 months } \\
\hline Children $0-6$ years old & 70 & 71 \\
\hline Elderly 60 and over & 75 & 77 \\
\hline \multicolumn{3}{|l|}{ Visited health practitioner last 12 months for check-up } \\
\hline Children $0-6$ years old & 57 & 59 \\
\hline Elderly 60 and over & 51 & 58 \\
\hline $\begin{array}{l}\text { If currently pregnant, visiting health practitioner for antenatal } \\
\text { care? }\end{array}$ & 73 & 81 \\
\hline$N$ & 12,175 & 11,886 \\
\hline
\end{tabular}


Figure 5. Impact estimates on attendance.

\begin{tabular}{|c|c|c|c|c|}
\hline & \multicolumn{4}{|c|}{ Specification } \\
\hline & 1 & 2 & 3 & 4 \\
\hline \multicolumn{5}{|l|}{ Reference period: } \\
\hline Participant group & $\begin{array}{c}0.483 * * * \\
(0.14)\end{array}$ & $\begin{array}{l}0.385 * \\
(0.22)\end{array}$ & $\begin{array}{l}0.443 * \\
(0.23)\end{array}$ & $\begin{array}{c}0.506^{* *} \\
(0.22)\end{array}$ \\
\hline Eligibility score & & $\begin{array}{c}-0.01 \\
(0.02)\end{array}$ & $\begin{array}{l}-0.008 \\
(0.02)\end{array}$ & $\begin{array}{l}-0.001 \\
(0.02)\end{array}$ \\
\hline Baseline school attendance & & & $\begin{array}{c}0.424 * * * \\
(0.02)\end{array}$ & $\begin{array}{c}0.406 * * * \\
(0.02)\end{array}$ \\
\hline Household controls & No & No & No & Yes \\
\hline$N$ & 7,751 & 7,751 & 6,850 & 6,819 \\
\hline \multicolumn{5}{|l|}{ Typical period: } \\
\hline Participant group & $\begin{array}{c}0.586^{* * * *} \\
(0.14)\end{array}$ & $\begin{array}{c}0.614 * * * \\
(0.21)\end{array}$ & $\begin{array}{c}0.527 * * * \\
(0.21)\end{array}$ & $\begin{array}{c}0.552 * * * \\
(0.21)\end{array}$ \\
\hline Eligibility score & & $\begin{array}{l}0.003 \\
(0.02)\end{array}$ & $\begin{array}{l}-0.002 \\
(0.02)\end{array}$ & $\begin{array}{l}0.003 \\
(0.02)\end{array}$ \\
\hline Baseline school attendance & & & $\begin{array}{c}0.405 * * * \\
(0.03)\end{array}$ & $\begin{array}{c}0.389 * * * \\
(0.03)\end{array}$ \\
\hline Household controls & No & No & No & Yes \\
\hline$N$ & 7,745 & 7,745 & 6,821 & 6,790 \\
\hline
\end{tabular}

Figure 6. Impact estimates on attendance for subgroups.

\begin{tabular}{lcc}
\hline & \multicolumn{2}{c}{ Impact estimate } \\
\cline { 2 - 3 } Subgroup & Reference period & Typical period \\
\hline Boys & 0.42 & 0.57 \\
Girls & 0.44 & 0.44 \\
\hline Kingston Metropolitan Area & 1.81 & 2.58 \\
Other urban & 0.96 & 1.03 \\
Rural & 0.35 & 0.2 \\
\hline Age 6-9 & 0.59 & 0.63 \\
Age 10-12 & 0.23 & 0.16 \\
Age 13-17 & 0.59 & 0.84 \\
\hline
\end{tabular}


Figure 7: Impact estimates on preventive health visits.

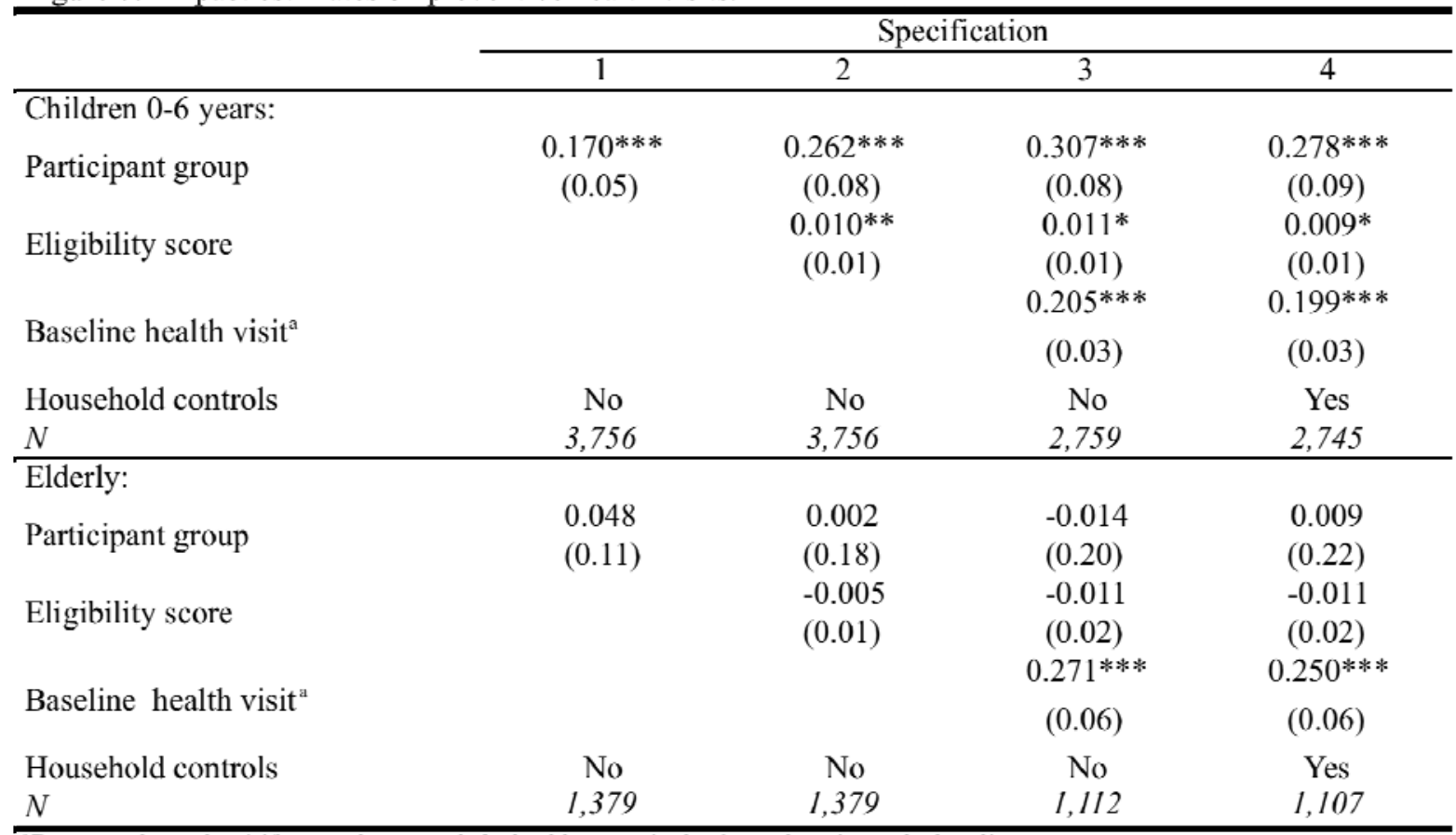

${ }^{a}$ Dummy takes value 1 if respondent attended a health centre in the 6 months prior to the baseline survey.

Standard errors in parenthesis.

Regressions were run at the individual level. Huber-White standard errors were used to account for within-family correlations.

$* / * * / * * *$ Coefficient statistically significant at the $10 \% / 5 \% / 1 \%$ significance level.

Figure 8. Impact estimates on preventive health visits for subgroups.

\begin{tabular}{lcc}
\hline & \multicolumn{2}{c}{ Impact Estimate } \\
\cline { 2 - 3 } Subgroup & Children $0-6$ years & Elderly \\
\hline Boys & 0.16 & -0.18 \\
Girls & 0.45 & -0.05 \\
\hline Kingston metropolitan area & -0.04 & 1.37 \\
Other & -0.27 & -0.68 \\
Rural & 0.29 & -0.04 \\
\hline Age $0-1$ & 0.84 & NA \\
Age 2-6 & 0.28 & NA \\
\hline
\end{tabular}


Figure 9. Robustness to participant group restrictions.

\begin{tabular}{|c|c|c|c|c|}
\hline & \multicolumn{2}{|c|}{ School Attendance } & \multicolumn{2}{|c|}{ Attendance at Health Centres } \\
\hline & Reference Period & Typical Period & Children $0-6$ years & Elderly \\
\hline \multicolumn{5}{|c|}{ Households with score greater than 1,025 : } \\
\hline Participant group & $\begin{array}{c}0.736 * * * \\
(0.282)\end{array}$ & $\begin{array}{l}1.064 * * * \\
(0.277)\end{array}$ & $\begin{array}{c}0.309 * * * \\
(0.111)\end{array}$ & $\begin{array}{l}-0.134 \\
(0.325)\end{array}$ \\
\hline Eligibility score & $\begin{array}{c}0.046 \\
(0.036)\end{array}$ & $\begin{array}{c}0.090 \\
(0.039)\end{array}$ & $\begin{array}{c}0.006 \\
(0.015)\end{array}$ & $\begin{array}{l}-0.020 \\
(0.051)\end{array}$ \\
\hline $\begin{array}{l}\text { Household controls } \\
N\end{array}$ & $\begin{array}{c}\text { Yes } \\
5,346\end{array}$ & $\begin{array}{c}\text { Yes } \\
5,343\end{array}$ & $\begin{array}{c}\text { Yes } \\
2,156\end{array}$ & $\begin{array}{l}\text { Yes } \\
882\end{array}$ \\
\hline \multicolumn{5}{|c|}{ Households with score greater than 1,030 : } \\
\hline Participant group & $\begin{array}{c}1.036 \\
(0.348)\end{array}$ & $\begin{array}{c}1.313 \\
(0.337)\end{array}$ & $\begin{array}{l}0.249 * \\
(0.145)\end{array}$ & $\begin{array}{l}-0.122 \\
(0.423)\end{array}$ \\
\hline Eligibility score & $\begin{array}{c}0.148 \\
(0.077)\end{array}$ & $\begin{array}{c}0.175 \\
(0.076)\end{array}$ & $\begin{array}{l}-0.013 \\
(0.036)\end{array}$ & $\begin{array}{l}-0.027 \\
(0.094)\end{array}$ \\
\hline $\begin{array}{l}\text { Household controls } \\
N\end{array}$ & $\begin{array}{c}\text { Yes } \\
4,382\end{array}$ & $\begin{array}{c}\text { Yes } \\
4,373\end{array}$ & $\begin{array}{c}\text { Yes } \\
1,707\end{array}$ & $\begin{array}{l}\text { Yes } \\
724\end{array}$ \\
\hline \multicolumn{5}{|c|}{ Households that applied prior to 2003 : } \\
\hline Participant group & $\begin{array}{l}0.482 * * \\
(0.241)\end{array}$ & $\begin{array}{c}0.717 * * * \\
(0.232)\end{array}$ & $\begin{array}{l}0.353 * * * \\
(0.093)\end{array}$ & $\begin{array}{l}-0.067 \\
(0.218)\end{array}$ \\
\hline Eligibility score & $\begin{array}{c}0.002 \\
(0.020)\end{array}$ & $\begin{array}{c}0.026 \\
(0.020)\end{array}$ & $\begin{array}{c}0.014 \\
(0.008)\end{array}$ & $\begin{array}{l}-0.017 \\
(0.021)\end{array}$ \\
\hline $\begin{array}{l}\text { Household controls } \\
N\end{array}$ & $\begin{array}{c}\text { Yes } \\
5,858\end{array}$ & $\begin{array}{c}\text { Yes } \\
5,850\end{array}$ & $\begin{array}{c}\text { Yes } \\
2,333\end{array}$ & $\begin{array}{l}\text { Yes } \\
975\end{array}$ \\
\hline
\end{tabular}

